\title{
Transfemoral sockets with vacuum-assisted suspension comparison of hip kinematics, socket position, contact pressure, and preference: Ischial containment versus brimless
}

\author{
Jason T. Kahle, MSMS, CPO, FAAOP; ${ }^{*}$ M. Jason Highsmith, PT, DPT, PhD, CP, FAAOP \\ School of Physical Therapy and Rehabilitation Sciences, University of South Florida, Tampa, FL
}

\begin{abstract}
The objective of this study was to investigate the effect of brimless compared with ischial ramus containment (IRC) prosthetic sockets when using vacuum-assisted suspension (VAS) on persons with a unilateral transfemoral amputation (TFA). A randomized crossover design with a $2 \mathrm{~d}$ accommodation was used. People with unilateral TFA $(n=9$ analyzed) were enrolled. Interventions were IRC VAS and brimless VAS sockets. Main outcome measures included coronal hip angle and vertical and lateral socket movement as measured by X-ray, skin pressure measured by Tekscan, and preference measured subjectively. The brimless design was statistically equivalent to IRC in all measured coronal hip angles and vertical and lateral socket displacement. The peak/stance mean pressure in the medial proximal aspect of the socket was $322 \mathrm{mmHg}$ in the IRC compared with $190 \mathrm{mmHg}$ in the brimless condition. Except for medial proximal pressure, no other measures reached statistical significance. All subjects reported the brimless design to be more comfortable than the IRC in short-term preference. Brimless VAS socket design may be a clinically viable choice for people with TFA.
\end{abstract}

Clinical Trial Registration: ClinicalTrials.gov; NCT01416129; "Southern bone \& joint study-Brimless sockets"; http://clinicaltrials.gov/ct2/show/NCT01416129

Key words: amputation, biomechanics, fluoroscope, ischial ramus containment, kinematics, prosthetic, suspension, transfemoral socket, vacuum-assisted suspension, X-ray.

\section{INTRODUCTION}

The prosthetic socket is the most important aspect of the prosthesis in that it connects the person with amputation's residual limb to the components and the ground during stance. A compromised connection between the femur and the ground creates imbalance and instability during ambulation for the person with a transfemoral amputation (TFA). In regard to the design of a TFA prosthetic socket, the current standard of care to achieve a stable stance-phase connection focuses on the proximal aspect of the socket. The most proximal aspect of the socket, the brim, includes ischial ramus containment (IRC) and associated trim lines proximal to the ischial tuberosity (IT). The reported benefits and purpose of IRC and the socket brim is to create a stance stability mechanism by forming a coronal bony lock with the pelvis, establishing a counterforce [1-2]. This lock reportedly prevents a lateral shift of the socket and resultant femoral

\footnotetext{
Abbreviations: $\mathrm{AB}=$ abduction, $\mathrm{AD}=$ adduction, $\mathrm{IRC}=$ ischial ramus containment, IT $=$ ischial tuberosity, TFA = transfemoral amputation, VAS = vacuum-assisted suspension. *Address all correspondence to Jason T. Kahle, MSMS, CPO, FAAOP; School of Physical Therapy and Rehabilitation Sciences, University of South Florida, 3515 East Fletcher Ave, Tampa, FL 33612; 813-416-3419; fax: 866-897-8797. Email: jkahle@health.usf.edu http://dx.doi.org/10.1682/JRRD.2013.01.0003
} 
abduction (AB) [1,3-4]. There are few data substantiating these proposed benefits. Therefore, optimal prosthetic socket brim design for TFA remains elusive [3,5-8].

Elements of the socket design also carry or suspend the prosthesis during the swing phase of gait. Enhanced suspension creates a more solid connection to the socket, which potentially creates less motion during swing, resulting in the perception of greater control and less prosthetic weight for the person with amputation [9-10]. Vacuum-assisted suspension (VAS) offers the person with amputation a dynamic form of suspension in that it can actively suspend through a manual or electronic pump. This dynamic suspension may provide a more positive link to the prosthesis and reduce prosthetic migration and socket movement (pistoning and lateral shifting) during gait and other activities such as sitting [9-10]. Reduced motion could increase control in swing and stance by establishing a more stable and healthy environment for the femur and thigh [9-11]. Because of new silicone liner and vacuum pump technology, maintaining VAS as a form of suspension has recently become an option for the person with TFA.

The benefits of dynamic VAS may provide the person with amputation with improved socket pressure distribution, daily volume management, rotational control, musculoskeletal stability, and reduced socket movement [910,12-13]. If VAS does favorably affect these variables for the TFA, then the IRC brim's purpose may be biomechanically diminished. Removal of the IRC brim could be beneficial by improving hygiene, comfort, and mobility and reducing perspiration and fitting complications [3-4,14]. It is presently unknown whether IRC brim removal would compromise hip angle, lateral pelvic shifting, skin pressure, socket position, and ultimately, a patient's regard for the fit of the socket. There are currently no data substantiating the effect of removing the IRC brim when using VAS in the TFA population. The contemporary TFA socket standard of care is the IRC design. Therefore, the purpose of this study was to determine whether a brimless socket would compromise coronal hip angle and socket movement, increase skin pressure, and be more preferable to patients than the standard of care IRC socket. We hypothesized that the IRC socket would maintain a more anatomic coronal femur position (adduction [AD]), create less lateral movement of the socket relative to the femur, and decrease medial-lateral and distal skin pressure during gait, but that subjects would prefer the brimless socket in this short-term analysis.

\section{METHODS}

The study design was a randomized crossover clinical trial with two socket conditions. Inclusion criteria were unilateral TFA with a minimum of 6 mo of definitive prosthetic use and the ability to independently ambulate with or without a walking aid at a community level. Subjects also needed to be able to tolerate IRC and brimless sockets as defined by the study protocol. Twelve participants with TFA were recruited from a local outpatient prosthetic practice and provided informed consent. All subjects were casted and fit for two separate sockets: (1) an IRC brim socket and (2) a brimless socket (Figure 1). To eliminate confounding, the same suspension and components were used. Alignments were duplicated and confirmed with a LASAR alignment tool (Ottobock North America; Minneapolis, Minnesota) statically once the prosthesis was fit. Subjects were given 2 wk to test the sockets initially, during which time the selected clinic recorded X-rays and fluoroscope as an addition to their clinical notes and medical justification. Subjects were randomly assigned offsite to either an IRC or a brimless socket. The subjects were then given $2 \mathrm{~d}$ to acclimate to the first randomly assigned

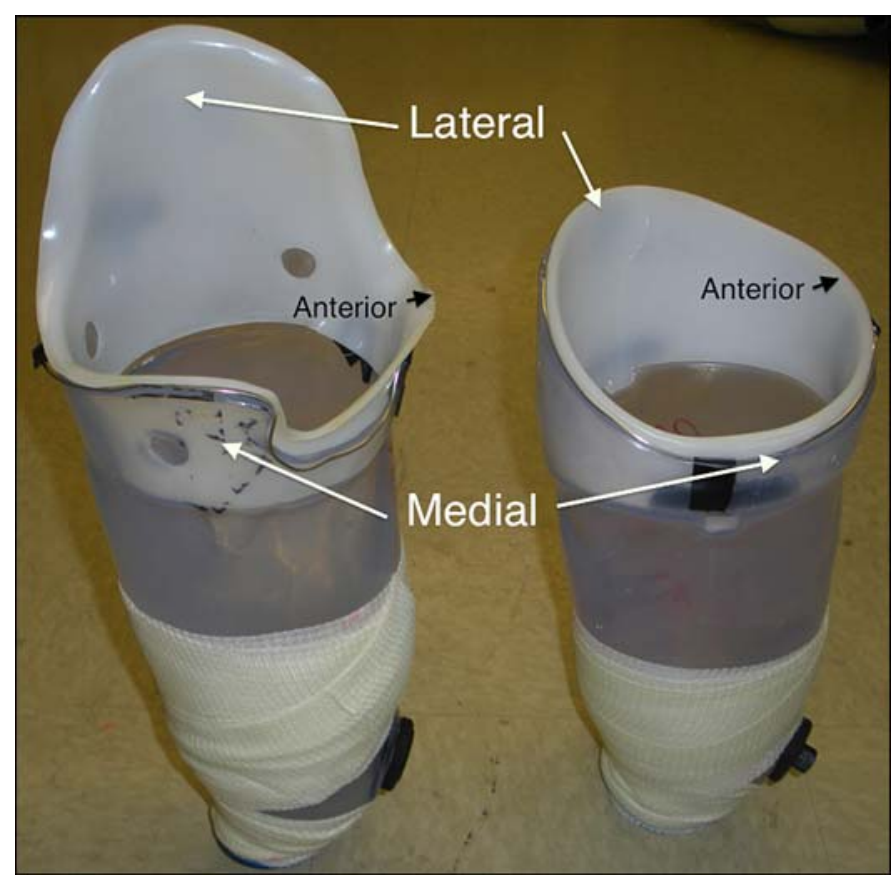

Figure 1.

Ischial ramus containment socket (left) compared with brimless socket (right) for same subject (left transfemoral amputation). Flexible material interface was used in proximal portion for both. 
socket and then tested. Immediately after the first testing, the subjects were fit into the alternate socket design. They were given $2 \mathrm{~d}$ to acclimate to the alternate socket and then retested.

\section{Design of Sockets}

Randomization would not have been possible with a single cast followed by an initial IRC socket fitting and eventual brim removal to create the brimless design. Therefore, two separate impressions were taken by hand over the same Symmetry liner (Symmetry Prosthetics; Dothan, Alabama) (Figure 2). The portion of the casts distal to the IT was volumetrically reduced by 6 percent globally through rectification. The brim portion of the socket for the IRC condition design was cast, rectified, and fit in accordance with the protocol described by Sabolich [1]. Static alignments (bench alignment) for both socket conditions were made in accordance with Long's line, where the center of the proximal aspect of the socket

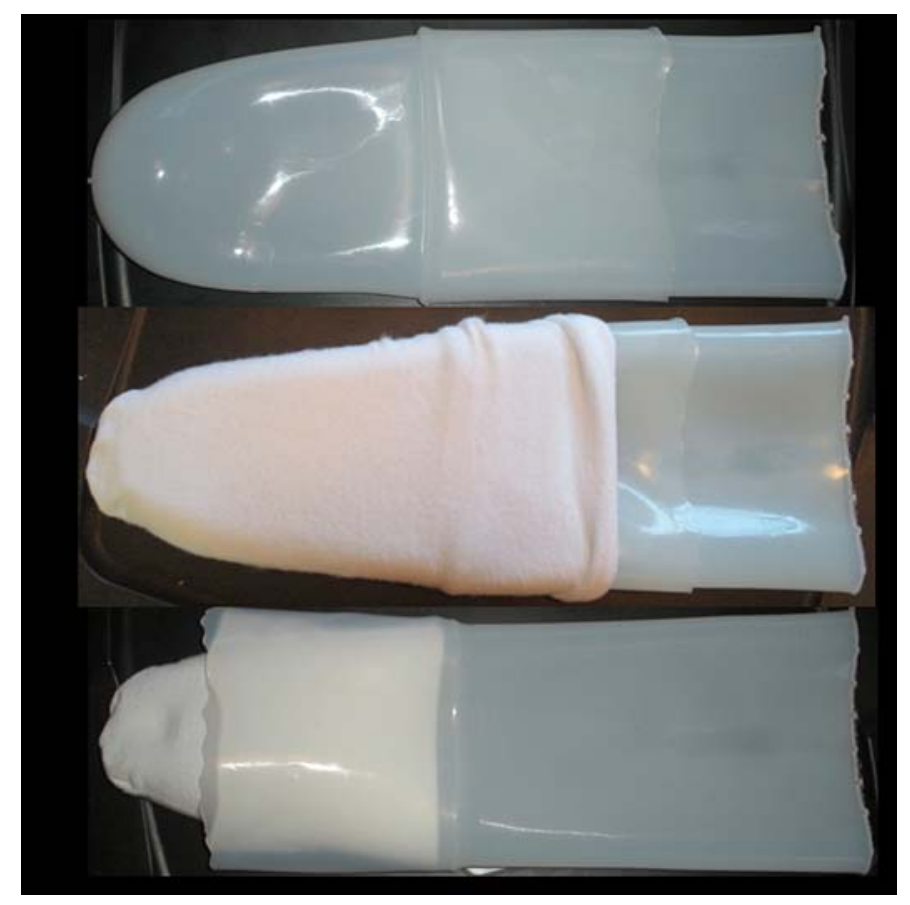

Figure 2.

Transfemoral Symmetry liner for vacuum-assisted suspension (VAS). Liner is donned and then sealing component (skirt) is rolled proximal. Wicking sock is donned (top) and then skirt is reflected distal (middle) to create interface seal for VAS (bottom). Area that sock covers would be under vacuum. Spray alcohol is then used over donned liner to insert residual limb into interface. is the proximal reference point [15]. All sockets were cast, modified, fit, aligned, and adjusted by the same licensed prosthetist, certified by the American Board for Certification in Orthotics, Prosthetics and Pedorthics. The prosthetist was also certified in fitting Symmetry TFA VAS systems, the Sabolich Socket Course, and the Ottobock Elevated Vacuum Socket Technology course. Both rigidframe sockets were fabricated with a flexible material interface in the proximal portion (Figure 1) to provide the maximum comfort proximally in either interface. For suspension, a transfemoral Symmetry liner was used in conjunction with an ePulse (Ottobock) electronic pump that provided VAS on both sockets. The trimline of the rigid frame in both sockets was lined with soldering iron to ensure clear definition during X-ray and fluoroscopy and to allow socket measurements. General Electric X-ray and fluoroscope machines (Fairfield, Connecticut) were used.

\section{Socket Position and Coronal Hip Angle}

As adjunct to the patient's records, the clinic used fluoroscope as a dynamic medium to visually confirm an appropriate fit from a coronal view [3]. A treadmill was placed beneath the fluoroscope to capture the coronal view of the pelvic region while walking. Prior to recording with the fluoroscope, subjects walked on the treadmill at their self-selected walking speed. Once this velocity was attained, the fluoroscope was activated and recordings were taken of three continuous strides as determined by observational gait analysis (Figure 3).

A coronal pelvic X-ray (Figure 4) was used to measure the medial wall height, vertical and lateral socket movement (pistoning and lateral shifting), and hip angle. While not as dynamically accurate [3,16-18], X-ray images can be more clear and encompassing. X-ray was used in addition to fluoroscope to ensure accurate recording of the interface in the event the fluoroscope did not provide a discernable difference. Subjects stood with their feet $10 \mathrm{~cm}$ apart in the following three conditions:

1. Bilateral equal weight bearing.

2. Simulated prosthetic stance phase in which subjects were asked to stand on the prosthetic side while minimally lifting the sound limb and pelvis and instructed to minimally deviate their heads from the center line.

3. Simulated prosthetic swing phase in which subjects were asked to minimally lift the prosthetic limb and pelvis while standing on the sound side and instructed to minimally deviate their heads from the center line. 


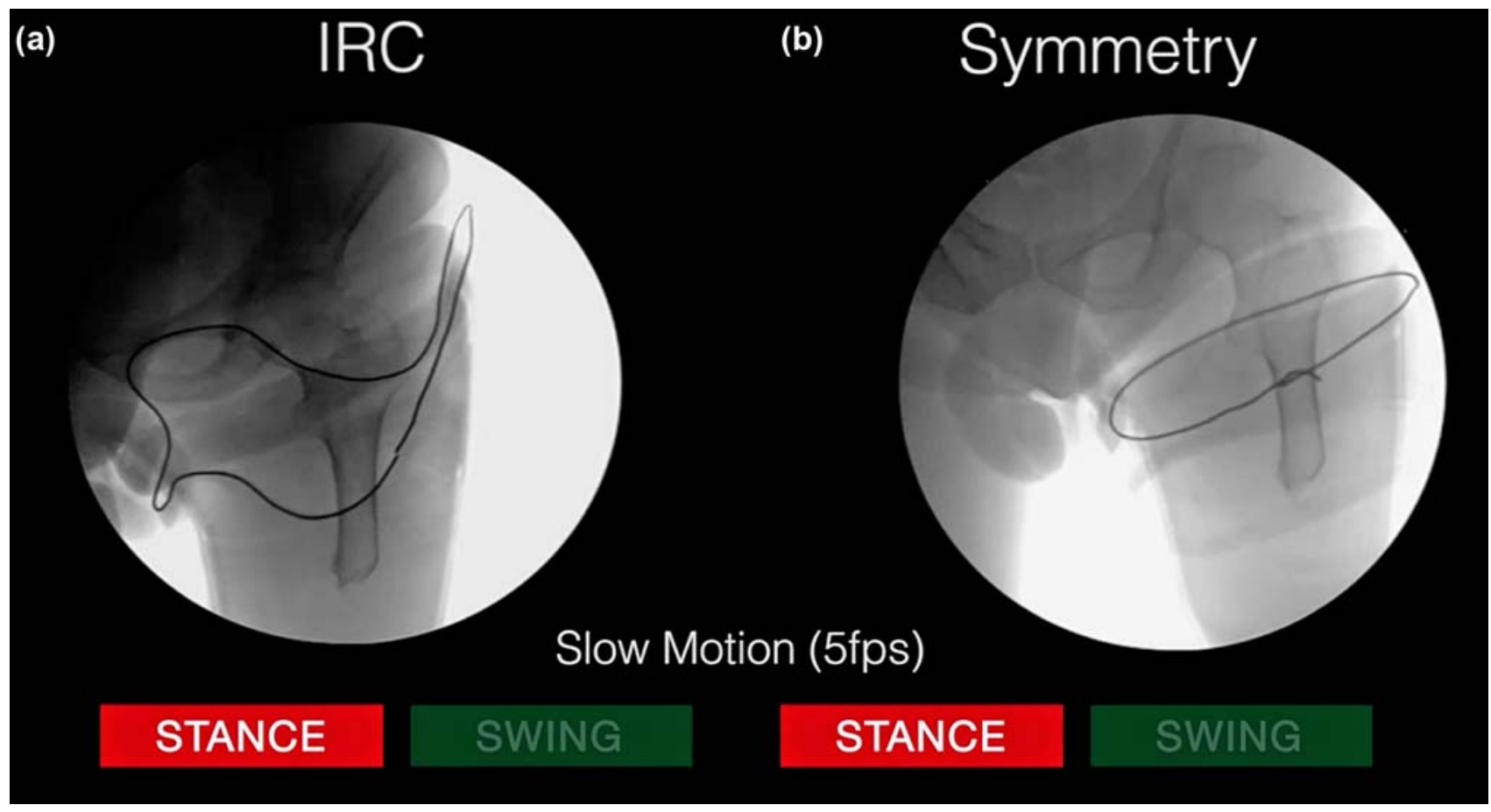

Figure 3.

Fluoroscope screen shot of subject 1 in (a) ischial ramus containment (IRC) and (b) brimless design during stance phase. fps = frames per second.
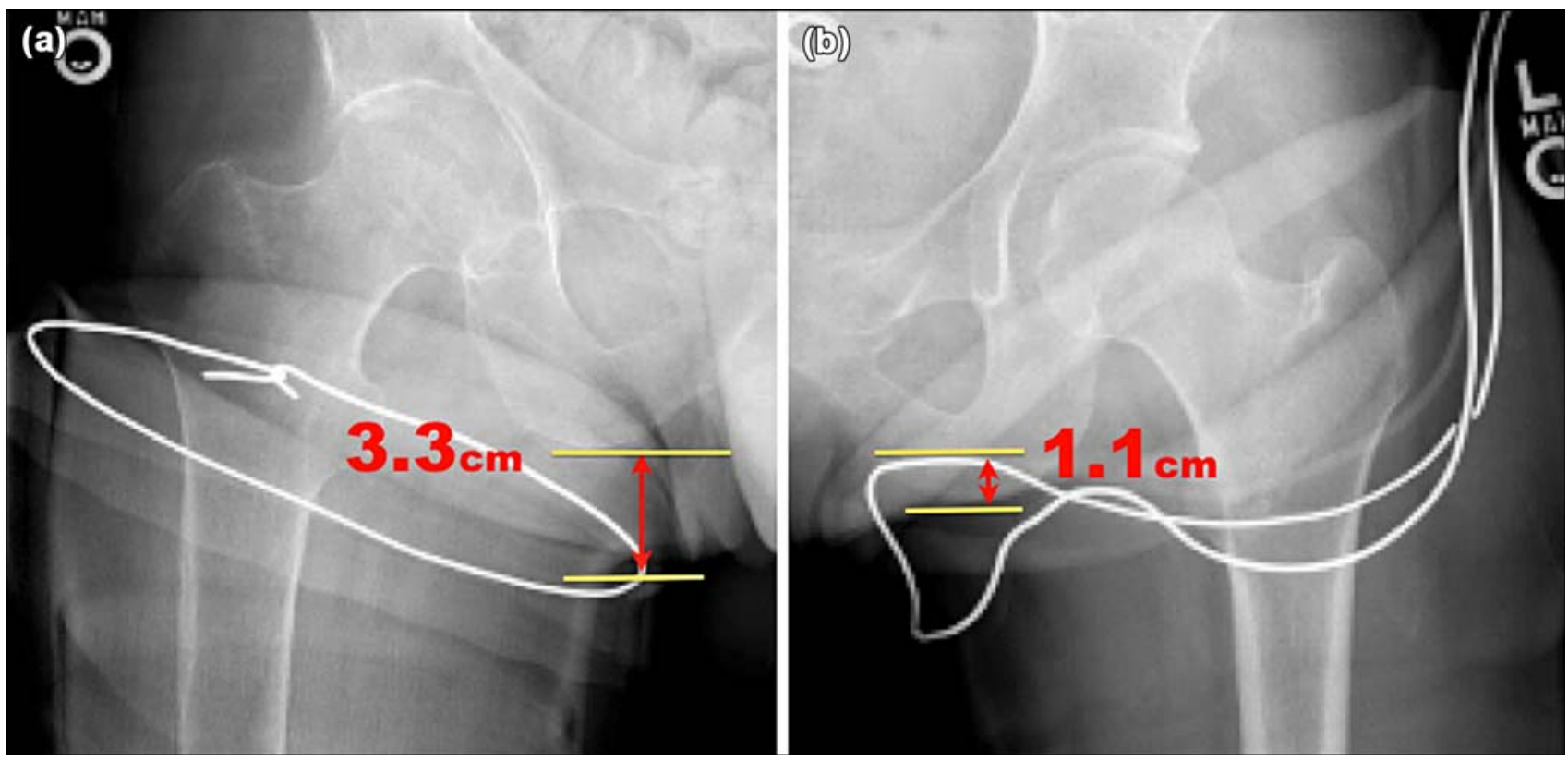

Figure 4.

X-ray comparison (different subjects with approximate to-scale representation of mean ischial ramus containment [IRC], both taken with equal weight bearing on both legs) of (a) brimless and (b) IRC sockets in relation to pelvis. Brimless sockets mean was $3.3 \mathrm{~cm}$ distal to ischial tuberosity (IT), whereas medial wall of IRC interfaces mean was $1.1 \mathrm{~cm}$ proximal to IT. Measurements were taken from medial-most proximal aspect of both sockets to most distal aspect of IT. 
Manual measurements were taken from the X-rays. Condition 1 was used to confirm IRC [19]. The measurement for medial wall height was taken vertically from the distal-most aspect of the IT to the most proximal aspect of the medial wall of each socket's rigid frame. Pistoning was measured as the vertical distance from the distalmost aspect of the IT to the most proximal aspect of the medial wall of each socket's rigid frame, measured as the difference between conditions 2 and 3. Lateral shifting was measured as the horizontal distance from the center of the symphysis pubis to the lateral aspect of the socket's rigid frame, measured as the difference between conditions 2 and 3.

\section{Socket Pressure}

Two pressure sensor arrays were placed as medialproximal as possible and distal laterally between subjects' skin and the liner to capture pressure profiles in this area of the socket. The liner ensured that the sensors were held in place and minimized migration. The proximal-medial sensor was placed at the proximal termination of the medial wall of the socket to remain within the rigid frame and then extended distal $20 \mathrm{~cm}$. The distal lateral sensor was positioned to cover the distal aspect of the residual limb and curved proximally and laterally such that the lateral distal femur would make contact with the sensor (Figure 5). Outlining the sensor with a marker on the skin during the first data collection and then using that same position in the second data collection duplicated the placement of the sensors. Subjects were asked to walk overground continuously until self-selected walking speed was attained. At that point, the pressure recordings of 15 gait cycles were recorded. The Tekscan F-Socket System (Tekscan Inc; Boston, Massachusetts) (two channel, $160 \mathrm{~Hz}, 7 \times 20 \mathrm{~cm}$ wide senor arrays, less than $1 \mathrm{~mm}$ thick, composed of 96 separate sensor cells [sensels], resolution of 4 sensels/in. ${ }^{2}$, range of 75 psi [3,879 mmHg]) was used to record pressure data. In the absence of an optimal alternative [20], sensor calibration was done in accordance with manufacturer recommendations. Calibration was performed immediately prior to data collection. The "peak/stance" averaging and the single greatest peak pressure (in a $2 \times 2$ sensels square) over the entire sensor array were reported. As defined by Tekscan, peak/stance averaging displays a single movie frame that is created by averaging a group of "peak" frames, or "stances" (a movie is divided into "stances" when the "Peak/Stance" menu item is selected). The individual sensel values for each of the "peak" frames were

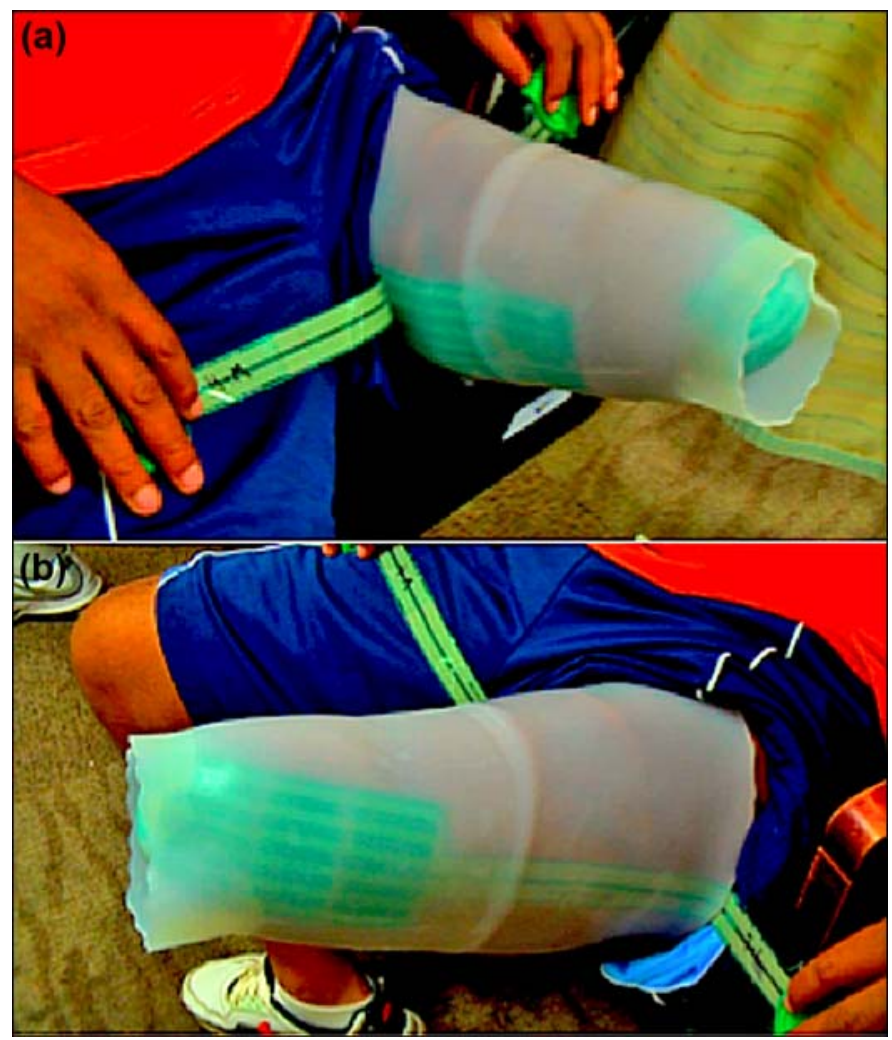

Figure 5.

Placement of pressure sensors: (a) as proximal and medial as socket rigid frame contours permit, and (b) directly on distal end and contoured distal laterally to capture pressure of distal lateral femur.

averaged and displayed as a composite "averaged stance." Pressures are reported in millimeters of mercury rather than kilopascals to facilitate interpretation with respect to circulation $(1 \mathrm{kPa}=7.5 \mathrm{mmHg}, 1 \mathrm{psi}=51.7 \mathrm{mmHg})$ [21]

\section{Socket Preference}

At the end of the second data collection, the subjects were given a protocol-specific form to complete in private. Subjects were asked which of the two socket conditions they preferred. Additionally, subjects were asked to narratively describe aspects of the sockets that they liked and disliked and to provide any comments in free form that they wished to express to the investigators.

\section{Statistical Analyses}

SPSS v20 (IBM Corporation; Armonk, New York) was used for statistical analysis. Paired $t$-tests were used to compare socket position and movement, coronal hip 
angle, and skin pressure when data were normally distributed. When data were abnormally distributed, the Wilcoxon signed-rank test for difference in medians was used. Statistical significance was set at $p \leq 0.05$.

\section{RESULTS}

Twelve subjects were recruited. Following fitting and prior to data collection, two subjects withdrew for unrelated acute medical reasons and one subject was excluded from the analysis due to not achieving IRC as verified with fluoroscopy, leaving $n=9$. The mean age was $41.2 \pm$ $14.5 \mathrm{yr}$ (range: $21-70 \mathrm{yr}$ ) and mean residual-limb length was $57.0 \pm 16.5$ percent (range: $33 \%-88 \%$ ) of the sound side femur length, measured from IT to distal end (for the residual limb) and medial tibial plateau (for sound side). Subjects' mean time with an amputation was $9.1 \pm 10.3 \mathrm{yr}$ (range: 0.8-26.0 yr) and mean Amputee Mobility Predictor score [22] was $40.3 \pm 6.7$ (range: 27-45). All subjects had medium or firm tissue consistency [19]. Three subjects wore a Symmetry liner brimless socket prior to this clinical trial. The remaining subjects wore an IRC socket and a variety of suspension systems (Table 1).

\section{Socket Position and Movement}

The mean medial wall height on the IRC sockets was $1.1 \mathrm{~cm}$ proximal to the distal-most aspect of the IT. The medial wall on the brimless design was a mean of $3.3 \mathrm{~cm}$ distal to the distal-most aspect of the IT (Figure 4). The mean lateral shifting in the brimless design was $1.6 \pm 0.7 \mathrm{~cm}$ (range: $0.5-2.5 \mathrm{~cm}$ ) compared with the IRC of $1.2 \pm 1.1 \mathrm{~cm}$ (range: $0-3.7 \mathrm{~cm}$ ). The mean vertical movement (pistoning) in the brimless socket design was $1.4 \pm 0.8 \mathrm{~cm}$ (range: 0.6-3.1 cm) compared with the IRC condition of $2.5 \pm 0.9 \mathrm{~cm}$ (range: $1.5-4.5 \mathrm{~cm}$ ) (Table 2). These differences did not reach statistical significance.

\section{Coronal Hip Angle}

In double support, less femoral $\mathrm{AB}$ was observed in the IRC design $\left(3.3^{\circ} \pm 7.1^{\circ}, 13.7 \mathrm{AB}-9.0 \mathrm{AD}\right)$ than with the brimless socket condition $\left(4.8^{\circ} \pm 5.6^{\circ}, 16.3 \mathrm{AB}-5.2 \mathrm{AD}\right)$. Similarly, in single support (prosthetic stance), less femoral $\mathrm{AB}$ was also observed in the IRC design $\left(0.9^{\circ} \pm 5.0^{\circ}\right.$, 7.0 AB-8.3 AD) than with the brimless socket condition $\left(1.2^{\circ} \pm 5.6^{\circ}, 9.6 \mathrm{AB}-10.2 \mathrm{AD}\right)$. In prosthetic swing phase, less femoral $\mathrm{AD}$ was noted in the IRC than with the brimless socket $\left(1.6^{\circ} \pm 3.7^{\circ}\right.$, $3.2 \mathrm{AB}-8.1 \mathrm{AD}$ vs $2.4^{\circ} \pm 2.9^{\circ}$, 3.1 AB-5.9 AD, respectively) (Table 2). However, these differences failed to reach significance for both prosthetic stance and swing.

\section{Skin Pressure}

The peak/stance average pressure in the medial proximal aspect of the socket was $322 \pm 210 \mathrm{mmHg}$ (range: 157$868 \mathrm{mmHg}$ ) in the IRC, compared with $190 \pm 103 \mathrm{mmHg}$ (range: $53-347 \mathrm{mmHg}$ ) in the brimless condition; this difference was statistically significant $(p=0.02)$. The peak/ stance average pressure of the distal lateral aspect was $188 \pm$ $70 \mathrm{mmHg}$ (range: 105-323 mmHg) in the IRC, compared with $222 \pm 113 \mathrm{mmHg}$ (range: 114-461 mmHg) in the brimless condition (Table 2). The single greatest peak pressure

Table 1.

Demographics $(n=9)$.

\begin{tabular}{|c|c|c|c|c|c|c|c|c|c|c|c|c|c|c|c|}
\hline Subject & Etiology & $\begin{array}{l}\text { Amputation } \\
\text { Side }\end{array}$ & $\begin{array}{l}\text { Age } \\
\text { (yr) }\end{array}$ & $\begin{array}{l}\text { Time After } \\
\text { Amputation } \\
\quad \text { (yr) }\end{array}$ & $\begin{array}{l}\text { Height } \\
\text { (cm) }\end{array}$ & $\begin{array}{c}\text { Weight } \\
\text { (kg) }\end{array}$ & $\begin{array}{c}\text { Tissue } \\
\text { Consistency }\end{array}$ & $\begin{array}{l}\text { AMP } \\
\text { Score }\end{array}$ & Sex & IRC ${ }^{*}$ & Brimless $^{\dagger}$ & $\begin{array}{l}\text { RL } \\
\text { Length } \\
(\mathbf{c m})\end{array}$ & $\begin{array}{l}\text { Sound } \\
\text { Femur } \\
(\%)\end{array}$ & $\begin{array}{l}\text { Socket } \\
\text { Type } \\
\text { Prior }\end{array}$ & $\begin{array}{c}\text { Prosthetic } \\
\text { Foot }\end{array}$ \\
\hline 1 & Sarcoma & $\mathrm{R}$ & 40 & 26 & 175 & 68 & Firm & 40 & $\mathrm{M}$ & 2.7 & 3.1 & 13 & 33 & IRC & C-walk \\
\hline J & Trauma & $\mathrm{L}$ & 37 & 4 & 180 & 84 & Firm & 43 & M & 0.1 & 1.9 & 37 & 88 & Brimless & C-walk \\
\hline 4 & Trauma & $\mathrm{L}$ & 50 & 2.5 & 160 & 76 & Medium & 27 & $\mathrm{~F}$ & 0.9 & 2.5 & 24 & 67 & IRC & Navigator \\
\hline 5 & Trauma & $\mathrm{R}$ & 48 & 14 & 183 & 84 & Medium & 46 & M & 0.8 & 6.2 & 20 & 41 & Brimless & Trias \\
\hline 7 & Trauma & $\mathrm{L}$ & 21 & 1.5 & 170 & 55 & Medium & 44 & $\mathrm{~F}$ & 0.9 & 5.7 & 26 & 64 & IRC & OB 1d35 \\
\hline 8 & PVD & $\mathrm{L}$ & 39 & 0.8 & 183 & 75 & Firm & 44 & M & 1.0 & 3.1 & 28 & 57 & IRC & Navigator \\
\hline 9 & Trauma & $\mathrm{R}$ & 42 & 26 & 188 & 95 & Firm & 45 & M & 1.4 & 2.7 & 27 & 55 & Brimless & Trias \\
\hline \multicolumn{16}{|c|}{$\begin{array}{l}\text { Note: All knees and feet are Ottobock Healthcare. All subjects' knees were C-legs, except for subject } 4 \text { who used 3R49. } \\
\text { *Length }(\mathrm{cm}) \text { proximal to ischial tuberosity in IRC sockets. } \\
\text { †Length }(\mathrm{cm}) \text { distal to ischial tuberosity in brimless sockets. } \\
\text { AMP = Amputee Mobility Predictor, F = female, IRC = ischial ramus containment, } \mathrm{L}=\text { left, } \mathrm{M}=\text { male, } \mathrm{PVD}=\text { peripheral vascular disease, } \mathrm{R}=\text { right, } \mathrm{RL}=\text { residual limb } \\
\end{array}$} \\
\hline
\end{tabular}


Table 2.

Results reported as mean \pm standard deviation (range).

\begin{tabular}{|c|c|c|}
\hline Outcome Measure & IRC & Brimless \\
\hline \multicolumn{3}{|l|}{ Interface Position and Movement (cm) } \\
\hline Ischial Containment Quantity & $1.1 \pm 0.9(0.1-2.7)^{*}$ & $3.3 \pm 1.6(1.5-6.2)^{\dagger}$ \\
\hline Lateral Shifting ${ }^{\ddagger}$ & $1.2 \pm 1.1(0-3.7)$ & $1.6 \pm 0.7(0.5-2.5)$ \\
\hline Pistoning & $2.5 \pm 0.9(1.5-4.5)$ & $1.4 \pm 0.8(0.6-3.1)$ \\
\hline \multicolumn{3}{|l|}{ Coronal Hip Angle $\left(^{\circ}\right)$} \\
\hline Double Support & $3.3 \pm 7.1 \mathrm{AB}(13.7 \mathrm{AB}-9.0 \mathrm{AD})$ & $4.8 \pm 5.6 \mathrm{AB}(16.3 \mathrm{AB}-5.2 \mathrm{AD})$ \\
\hline Simulated Prosthetic Swing (single support on contralateral side) & $1.6 \pm 3.7 \mathrm{AD}(3.2 \mathrm{AB}-8.1 \mathrm{AD})$ & $2.4 \pm 2.9 \mathrm{AD}(3.1 \mathrm{AB}-5.9 \mathrm{AD})$ \\
\hline \multicolumn{3}{|l|}{ Skin Pressure $(\mathrm{mmHg})^{\S}$} \\
\hline \multicolumn{3}{|l|}{ Peak/Stance Average } \\
\hline Medial Proximal $^{\ddagger}$ & $322 \pm 210(157-868)$ & $190 \pm 103(53-347)$ \\
\hline Distal Lateral & $188 \pm 70(105-323)$ & $222 \pm 113(114-461)$ \\
\hline
\end{tabular}

*This value is proximal to ischial tuberosity.

${ }^{\dagger}$ This value is distal to ischial tuberosity.

‡These data were abnormally distributed.

${ }^{\S}$ Pressures are reported in millimeters of mercury, rather than kilopascals, to facilitate interpretation with respect to circulation $(1 \mathrm{kPa}=7.5 \mathrm{mmHg} ; 1 \mathrm{psi}=51.7 \mathrm{mmHg})$. $\mathrm{AB}=$ abduction, $\mathrm{AD}=$ adduction, $\mathrm{IRC}=$ ischial ramus containment.

value in the medial-proximal aspect of the socket was $841 \pm$ $600 \mathrm{mmHg}$ (range: $280-1,910 \mathrm{mmHg}$ ) in the IRC compared with $819 \pm 455 \mathrm{mmHg}$ (range: $256-1,668 \mathrm{mmHg}$ ) in the brimless condition and distal laterally $543 \pm 328 \mathrm{mmHg}$ (range: 222-1,069 mmHg) in the IRC compared with $751 \pm$ $562 \mathrm{mmHg}$ (range: 317-1,824 mmHg) in the brimless condition (Table 2). These differences were not statistically significant.

\section{Socket Preference}

All subjects preferred the brimless socket to the IRC. The most common narrative description was increased comfort in sitting and standing related to the brimless design. A decrease in phantom and low-back pain, an increase in hip range of motion, less urogenital interference, and ease in walking were also common themes related to the brimless design.

\section{DISCUSSION}

While we hypothesized superiority of the IRC socket in femoral position, skin pressure, and socket movement, this was not the case. In this sample, the brimless design was essentially equivalent to the IRC in most outcome measures, except for medial proximal skin pressure. Regarding preference, our hypothesis was correct in that the brimless design was chosen. The literature suggests a brim may assist in pelvic stabilization, prevent lateral shifting, and maintain an adducted femur position $[1,4]$. However, the subsequent perineal discomfort associated with an IRC brim could potentially cause an abducted positioning of the thigh and femur by crowding the perineal region. Additionally, some researchers have stated that socket design has no influence on femur position [6,23-26]. In this study, we observed no significant differences in coronal hip angle and lateral shifting between the IRC and brimless socket designs. This is not to say that IRC and a corresponding brim are invalid. IRC may enhance pelvic stability through the coronal dimension of the IRC and the proximal lateral wall while having no effect or reliance on the femur as previously hypothesized in the literature [1-2]. Additionally, the brim may play a kinesthetic role in guiding the residual limb through an adducted position during swing phase, for instance [3]. In this study, coronal hip angle is largely unaffected by removal of the brim, the region credited with stabilizing the femur through the bony lock.

Compared with passive conventional options, a dynamic suspension method that increases the surface 
area [2] for VAS and total-contact weight bearing likely contributed to the ability to successfully fit this sample of TFAs with brimless VAS sockets. Symmetry transfemoral liners are specifically designed as a TFA VAS liner system. This VAS technology provides a repeatable protocol in that the sealing sleeve and liner are incorporated into a single design. Additionally, Symmetry liners allow for a seal that is positioned as proximal as possible in the socket. The area that is then used to achieve VAS is also used to achieve the connection to the socket through the reflective sealing component (Figure 2). In a sample of people with transtibial amputation, Klute et al. observed a reduction in pistoning from $6 \mathrm{~mm}$ with pin suspension to $1 \mathrm{~mm}$ with VAS [10]. They concluded that VAS could result in a superior fitting socket because it minimizes pistoning. Because we used VAS in both socket conditions, a difference in pistoning between them was not anticipated. The addition of IRC did result in a trend of increased pistoning. The relationship between the proximal support of an IRC socket and the dynamic distal pulling created by VAS may have contributed to a twofold increase in pistoning on the residual limb. While this difference failed to reach statistical significance in this sample, minimizing pistoning is of clinical significance. Symmetry liners were used as suspension for both the IRC and brimless socket designs. Future research should test other suspension methods in conjunction with a brimless design.

Neumann et al. reported $333 \mathrm{mmHg}$ average pressure at the ischium of an IRC socket at midstance in a single case [21], which is comparable with the $322 \mathrm{mmHg}$ observed in this study. The elimination of the IRC and subsequent reduction of load-bearing area would intuitively increase skin pressures on the residuum. This was not the case in the proximal medial aspect of the socket. In fact, there was a statistically significant reduction in mean skin pressure in the medial aspect when the IRC brim was removed. This could potentially be the result of a redistribution of pressure to other regions of the socket. Lee et al. [8] and Krouskop et al. [7] compared the pressures generated by quadrilateral and IRC sockets. Significant variations were noted in pressure distribution between the two socket designs, particularly in the anterior and posterior walls, but the magnitudes of the pressures in wellfitting sockets of both types were similar [7-8].

The single greatest peak pressure increased in the brimless sockets in the distal and distal-lateral femur areas, but not significantly. This result is surprising since there seems to be a redistribution of pressure as previously indicated, but statistically significant pressure redistribution was not observed in these two locations. This is of clinical interest because the distal and lateral-distal femur areas are specifically discussed in the literature and known to be problematic [4]. In this study, pressure was not measured throughout the entire socket. Knowing the entire pressure distribution may be helpful in understanding the dynamics of a VAS TFA socket.

Patient's tolerance for average pressure and a single greatest pressure would be beneficial in discerning the clinical significance of skin pressure. In an early study of pressure, circumferential application of $200 \mathrm{mmHg}$ was established as a pain threshold relative to pressure [27]. More recently, researchers have stated that muscle cell death can occur in less than 3 to $6 \mathrm{hr}$ with as little as $68 \mathrm{mmHg}$ [28-34]. The nondisabled person experiences negligible pressure on the ischium while standing and ambulating. In sitting, however, the nondisabled person experiences pressures as high as $300 \mathrm{mmHg}$ on the IT [35]. This is a considerable value in sensory and mobilityimpaired nondisabled individuals from a wound development and healing perspective relative to ischemic tissue responses. Presuming use of an IRC socket, the TFA will have pressure application to the tissues around the ischium not only while sitting but also during standing, ambulation, and potentially even during swing phase. Stage 1 pressure ulceration and the accompanying hyperemic skin response may be observed in as little as $30 \mathrm{~min}$ of contact without relief. Tissue ischemia will follow in 2 to $6 \mathrm{~h}$ if relief is not provided [35]. Given that the IRC socket contacts the ischium in gait with pressure magnitudes well in excess of $200 \mathrm{mmHg}$ and that there is constant contact regardless of functional activity, it is apparent that IRC users can experience tissue discoloration, callus, ischemia, and discomfort from use of an IRC socket design. We observed mean pressures of $322 \mathrm{mmHg}$ in the IRC, compared with $190 \mathrm{mmHg}$ in the brimless design. A reduction in medial skin pressure likely has a role in explaining the unanimous preference for the brimless socket. Narratively, these subjects translated the decrease in pressure to this specific area as an increase in comfort. Intuitively, patients would prefer lowering the medial wall of a socket in this sensitive region of the anatomy. Interestingly, all of these subjects did prefer the brimless socket.

$\mathrm{X}$-ray was more reliable when considering factors such as drop-out, readability, clarity, and reliability. However, Xray is not dynamic and therefore may not be as accurate as 
other media, such as fluoroscope and ultrasound [3,16-17]. These media also have limitations; therefore, a compromise may need to be recognized when evaluating dynamic skeletal kinematics. Acclimation to a prosthetic socket is crucial relative to function and preference. However, the excess time needed to acclimate to an experimental intervention can lead to higher attrition for subjects who are intolerant of socket changes [10]. This can make it difficult to recruit and retain subjects, which can lead to low study power. Additionally, it would be impossible to blind subjects as to whether or not IRC is present. These factors are problematic in designing socket studies and were limitations in this study. Most subjects would instinctively prefer less socket surface area unless they observed compromise to gait and comfort. All subjects in this study preferred the brimless socket in the short-term. It is unclear whether they would prefer the brimless and whether the functional effects would be comparable in a long-term study.

Future studies should also observe overall gait kinetics and kinematics. Defining overall gait deviations is an important but challenging goal of determining efficacy of prosthetic interventions. Energetics have been observed in past TFA socket comparisons [36-38] and would be a beneficial comparison in IRC versus a brimless design using VAS with higher-functioning subjects. Establishing the effect of brim design on the stability and balance of lower-functioning TFAs would also be beneficial. TFAs can be difficult to fit [4] because of prosthetists' and researchers' lack of consensus on technique, skillset, experience, and applicable materials. TFA VAS is a new technique that requires significant experience to achieve a viable fit and therefore a valid comparison. Using a repeatable technique is imperative. IRC can also be difficult to fit and quantify. An adequate amount of IRC needs to be balanced with comfort and tolerance for each subject. A prosthetist's ability to achieve cohesive and repeatable prosthetic socket designs is essential in any socket study. Further research is necessary to better understand TFA socket design options.

\section{CONCLUSIONS}

Elimination of the brim may be a clinically viable choice of socket for TFAs because the brimless design was equivalent to the IRC in the area of coronal hip angle, vertical movement, and lateral shifting. Mean peak stance skin pressure was less in the medial proximal aspect of the brimless design. All other peak and mean skin pressures were shown to be equivalent when comparing the brimless design with the IRC. The brimless design was reported to be more comfortable than the IRC design in short-term preference.

\section{ACKNOWLEDGMENTS}

\section{Author Contributions:}

Study concept and design: J. T. Kahle. Acquisition of data: J. T. Kahle.

Analysis and interpretation of data: J. T. Kahle, M. J. Highsmith. Drafting of manuscript: J. T. Kahle, M. J. Highsmith.

Critical revision of manuscript for important intellectual content:

J. T. Kahle, M. J. Highsmith.

Statistical analysis: M. J. Highsmith.

Obtained funding: M. J. Highsmith, J. T. Kahle.

Administrative, technical, or material support: M. J. Highsmith.

Study supervision: J. T. Kahle, M. J. Highsmith.

Financial Disclosure: The authors have declared that no competing interests exist.

Funding/Support: This material was based on work supported by the University of South Florida (grant USF\# 6140101600).

Institutional Review: This protocol was approved by the University of South Florida's Institutional Review Board.

Participant Follow-Up: The authors do not plan to inform participants of the publication of this study. However, participants have been encouraged to check the study Web site for updated publications.

\section{REFERENCES}

1. Sabolich J. Contoured adducted trochanteric-controlled alignment method (CAT-CAM): Introduction and basic principles. Clin Prosthet Orthot. 1985;9(4):15-26.

2. Redhead RG. Total surface bearing self suspending aboveknee sockets. Prosthet Orthot Int. 1979;3(3):126-36. [PMID:523290]

3. Kahle JT. A case study using fluoroscope to determine the vital elements of transfemoral interface design. J Prosthet Orthot. 2002;14(3):121-26. http://dx.doi.org/10.1097/00008526-200209000-00007

4. Bowker JH. Atlas of limb prosthetics: Surgical, prosthetic, and rehabilitation principles. 2nd ed. St. Louis: Mosby Year Book; 2002.

5. Krebs DE, Tashman S. Kinematic and kinetic comparison of the conventional and ISNY above-knee socket. Clin Prosthet Orthot. 1985;9(3):28-36.

6. Gottschalk FA, Kourosh S, Stills M, McClellan B, Roberts J. Does socket configuration influence the position of the femur in above-knee amputation? J Prosthet Orthot. 1989; 2(1):94-102. 
7. Krouskop TA, Brown J, Goode B, Winningham D. Interface pressures in above-knee sockets. Arch Phys Med Rehabil. 1987;68(10):713-14. [PMID:3662780]

8. Lee VS, Solomonidis SE, Spence WD. Stump-socket interface pressure as an aid to socket design in prostheses for trans-femoral amputees-a preliminary study. Proc Inst Mech Eng H. 1997;211(2):167-80. [PMID:9184457] http://dx.doi.org/10.1243/0954411971534287

9. Board WJ, Street GM, Caspers C. A comparison of transtibial amputee suction and vacuum socket conditions. Prosthet Orthot Int. 2001;25(3):202-9. [PMID:11860094] http://dx.doi.org/10.1080/03093640108726603

10. Klute GK, Berge JS, Biggs W, Pongnumkul S, Popovic Z, Curless B. Vacuum-assisted socket suspension compared with pin suspension for lower extremity amputees: Effect on fit, activity, and limb volume. Arch Phys Med Rehabil. 2011;92(10):1570-75. [PMID:21963124] http://dx.doi.org/10.1016/j.apmr.2011.05.019

11. Bennett L, Kavner D, Lee BK, Trainor FA. Shear vs pressure as causative factors in skin blood flow occlusion. Arch Phys Med Rehabil. 1979;60(7):309-14. [PMID:454129]

12. Beil TL, Street GM, Covey SJ. Interface pressures during ambulation using suction and vacuum-assisted prosthetic sockets. J Rehabil Res Dev. 2002;39(6):693-700. [PMID:17943671]

13. Beil TL, Street GM. Comparison of interface pressures with pin and suction suspension systems. J Rehabil Res Dev. 2004;41(6A):821-28. [PMID:15685470] http://dx.doi.org/10.1682/JRRD.2003.09.0146

14. Klotz R, Colobert B, Botino M, Permentiers I. Influence of different types of sockets on the range of motion of the hip joint by the transfemoral amputee. Ann Phys Rehabil Med. 2011;54(7):399-410. [PMID:21996548] http://dx.doi.org/10.1016/j.rehab.2011.08.001

15. Long IA. Normal shape-normal alignment (NSNA) aboveknee prosthesis. Clin Prosthet Orthot. 1985;9(4):9-14.

16. Convery P, Murray KD. Ultrasound study of the motion of the residual femur within a trans-femoral socket during gait. Prosthet Orthot Int. 2000;24(3):226-32. [PMID:11195358] http://dx.doi.org/10.1080/03093640008726552

17. Convery PM, Murray KD. Ultrasound study of the motion of the residual femur within a trans-femoral socket during daily living activities other than gait. Prosthet Orthot Int. 2001;25(3):220-27. [PMID:11860096] http://dx.doi.org/10.1080/03093640108726605

18. Portnoy SY, Yizhar Z, Shabshin N, Itzchak Y, Kristal A, Dotan-Marom Y, Siev-Ner I, Gefen A. Internal mechanical conditions in the soft tissues of a residual limb of a transtibial amputee. J Biomech. 2008;41(9):1897-1909. [PMID:18495134] http://dx.doi.org/10.1016/j.jbiomech.2008.03.035
19. Prosthetics 621: Transfemoral prosthetics for prosthetists. Course manual. Chicago (IL): Northwestern University. Feinberg School of Medicine Prosthetic-Orthotic Center; 2004.

20. Redd CB, Sanders JE. Considerations when using force sensitive resistors to measure socket interface pressure. Proceedings of the 39th Annual Meeting and Scientific Symposium of the American Academy of Orthotists and Prosthetists; 2013 Feb 20-23; Orlando, FL.

21. Neumann ES, Wong JS, Drollinger RL. Concepts of pressure in an ischial containment socket: Measurement. J Prosthet Orthot. 2005;17(1):2-11. http://dx.doi.org/10.1097/00008526-200501000-00003

22. Gailey RS, Roach KE, Applegate EB, Cho B, Cunniffe B, Licht S, Maguire M, Nash MS. The Amputee Mobility Predictor: An instrument to assess determinants of the lowerlimb amputee's ability to ambulate. Arch Phys Med Rehabil. 2002;83(5):613-27. [PMID:11994800]

23. Gottschalk F. CAT-CAM above-knee prostheses and the effect on functional rehabilitation. Clin Orthop Relat Res. 1990;(255):310-12. [PMID:2347163]

24. Gottschalk F. Transfemoral amputation. Biomechanics and surgery. Clin Orthop Relat Res. 1999;(361):15-22. [PMID:10212591] http://dx.doi.org/10.1097/00003086-199904000-00003

25. Gottschalk F, Orth F. Transfemoral amputation: Surgical procedures. In: Bowker JH, editor. Atlas of limb prosthetics: Surgical, prosthetic, and rehabilitation principles. 2nd ed. St Louis (MI): Mosby Year Book; 1992.

26. Gottschalk FA, Stills M. The biomechanics of trans-femoral amputation. Prosthet Orthot Int. 1994;18(1):12-17. [PMID:8084744]

27. Hardy JD, Wolff HG, Goodell H. Studies on pain. A new method for measuring pain threshold: Observations on spatial summation of pain. J Clin Invest. 1940;19(4):649-57. [PMID:16694782] http://dx.doi.org/10.1172/JCI101168

28. European Pressure Ulcer Advisory Panel [Internet]. Oxford (United Kingdom): European Pressure Ulcer Advisory Panel; 1996 [cited 2013 Jan 3]. Available from: http://www.epuap.org

29. Portnoy S, Siev-Ner I, Shabshin N, Gefen A. Effects of sitting postures on risks for deep tissue injury in the residuum of a transtibial prosthetic-user: A biomechanical case study. Comput Methods Biomech Biomed Engin. 2011;14(11): 1009-19. [PMID:20694863] http://dx.doi.org/10.1080/10255842.2010.504719

30. Portnoy S, Siev-Ner I, Shabshin N, Kristal A, Yizhar Z, Gefen A. Patient-specific analyses of deep tissue loads post transtibial amputation in residual limbs of multiple prosthetic users. J Biomech. 2009;42(16):2686-93. [PMID:19766225] http://dx.doi.org/10.1016/j.jbiomech.2009.08.019 
31. Portnoy S, van Haare J, Geers RP, Kristal A, Siev-Ner I, Seelen HA, Oomens CW, Gefen A. Real-time subjectspecific analyses of dynamic internal tissue loads in the residual limb of transtibial amputees. Med Eng Phys. 2010; 32(4):312-23. [PMID:20074994] http://dx.doi.org/10.1016/j.medengphy.2009.12.006

32. Oomens CW, Bressers OF, Bosboom EM, Bouten CV, Blader DL. Can loaded interface characteristics influence strain distributions in muscle adjacent to bony prominences? Comput Methods Biomech Biomed Engin. 2003; 6(3):171-80. [PMID:12888429] http://dx.doi.org/10.1080/1025584031000121034

33. Oomens CW, van Campen DH, Grootenboer HJ. A mixture approach to the mechanics of skin. J Biomech. 1987;20(9): 877-85. [PMID:3680313] http://dx.doi.org/10.1016/0021-9290(87)90147-3

34. Linder-Ganz E, Engelberg S, Scheinowitz M, Gefen A. Pressure-time cell death threshold for albino rat skeletal muscles as related to pressure sore biomechanics. J Biomech. 2006;39(14):2725-32. [PMID:16199045] http://dx.doi.org/10.1016/j.jbiomech.2005.08.010

35. Sussman CB, Bates-Jensen BM. Wound care: A collaborative practice manual for health professionals. 4th ed. Philadelphia (PA): Wolters Kluwer Health/Lippincott Williams \& Wilkins; 2012.

36. Gailey RS, Lawrence D, Burditt C, Spyropoulos P, Newell C, Nash MS. The CAT-CAM socket and quadrilateral socket: A comparison of energy cost during ambulation. Prosthet Orthot Int. 1993;17(2):95-100. [PMID:8233775]

37. Flandry F, Beskin J, Chambers RB, Perry J, Waters RL, Chavez R. The effect of the CAT-CAM above-knee prosthesis on functional rehabilitation. Clin Orthop Relat Res. 1989;(239):249-62.

38. Hachisuka KY, Umezu Y, Ogata H, Ohmine S, Shinkoda K, Arizono H. Subjective evaluations and objective measurements of the ischial-ramal containment prosthesis. J UOEH. 1999;21(2):107-18. [PMID:10434359]

Submitted for publication January 7, 2013. Accepted in revised form May 20, 2013.

The article and any supplementary material should be cited as follows:

Kahle JT, Highsmith MJ. Transfemoral sockets with vacuum-assisted suspension comparison of hip kinematics, socket position, contact pressure, and preference: Ischial containment versus brimless. J Rehabil Res Dev. 2013; 50(9):1241-52.

http://dx.doi.org/10.1682/JRRD.2013.01.0003

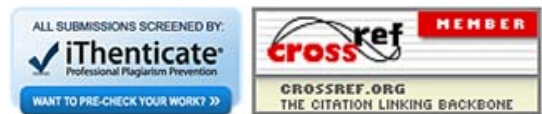


